\title{
Case Report: Congenital left ventricular diverticulum: a
}

\section{pediatric case report [version 1; peer review: 2 approved with}

\section{reservations]}

\author{
Myriam Jrad, Meriem Affes, Salma Behi, Amine Laabidi, Habiba Mizouni
}

Department of Radiology, La Rabta Hospital, Tunis, Tunisia

\author{
V1 First published: 03 Nov 2016, 5:2628 \\ https://doi.org/10.12688/f1000research.9936.1 \\ Latest published: 03 Nov 2016, 5:2628 \\ https://doi.org/10.12688/f1000research.9936.1
}

\begin{abstract}
Congenital left ventricular diverticulum is a rare cardiac abnormality consisting of a localized outpouching from the free wall of the cardiac chamber. It is usually asymptomatic. However, complications such as infective endocarditis, arrhythmias, and embolism may occur. Medical ultrasound, echocardiography, CT angiography, MRI and invasive ventriculography are diagnostic tools used to identify congenital left ventricular diverticulum. Surgical resection is the treatment of choice in symptomatic patients, whereas the management of asymptomatic patients often represents a therapeutic dilemma. We report the case of a symptomatic left ventricular diverticulum on a 3-day-old female with Cantrell's syndrome treated surgically. Postoperative course was uneventful. The patient was discharged with a good clinical condition. The prognosis of this malformation is poor if not diagnosed in the perinatal period. A diagnosis can be suspected with echocardiography; however, a CT scan allows a complete study of the problem. The treatment is always surgical with a good postoperative prognosis.
\end{abstract}

\section{Keywords}

CT angiography, MRI, left ventriculum, echocardiography

Open Peer Review
Approval Status ?
version 1
1. Mazeni Alwi, Institut Jantung Negara, Kuala
Lumpur, Malaysia
Institute of Circulation Pathology,
Novosibirsk, Russian Federation
Any reports and responses or comments on the
article can be found at the end of the article.

Corresponding author: Myriam Jrad (myriamjrad@gmail.com)

Competing interests: No competing interests were disclosed.

Grant information: The author(s) declared that no grants were involved in supporting this work.

Copyright: $\odot 2016 \mathrm{Jrad} \mathrm{M}$ et al. This is an open access article distributed under the terms of the Creative Commons Attribution License, which permits unrestricted use, distribution, and reproduction in any medium, provided the original work is properly cited.

How to cite this article: Jrad M, Affes M, Behi S et al. Case Report: Congenital left ventricular diverticulum: a pediatric case report [version 1; peer review: 2 approved with reservations] F1000Research 2016, 5:2628 https://doi.org/10.12688/f1000research.9936.1

First published: 03 Nov 2016, 5:2628 https://doi.org/10.12688/f1000research.9936.1 


\section{Introduction}

Congenital left ventricular diverticulum is a rare cardiac abnormality, consisting of a localized out pouching from the free wall of the cardiac chamber. Commonly, this is from the left ventricular apex; however, non-apical diverticula may also occur ${ }^{1}$. There are two types of ventricular diverticulum: muscular or fibrotic ${ }^{2}$.

Ventricular diverticulum is usually associated with a thoracoabdominal wall defect as seen in the spectrum of Cantrell's pentalogy $y^{1,2}$. Cantrell's syndrome is a very rare congenital disease, described by Cantrell, Haller, and Ravitch in 1958, associating a lower sternal defect, a supraumbilical abdominal wall defect, a deficiency of the anterior portion of the diaphragm, a deficiency in the diaphragmatic portion of the pericardium, and cardiac malformations ${ }^{3}$.

This study reports a rare case of a left ventricular diverticulum on a new born infant with Cantrell's syndrome.

\section{Case report}

A 3-day-new born African female, resulting from an irregularly monitored pregnancy, was referred to the Department of Pediatric Surgery of la Rabta Hospital of Tunisia for the investigation of an umbilical mass measuring $3 \mathrm{~cm}$ in diameter. The baby was the first child of parents with no history of familial disease, and there was no significant antenatal history. Clinical examination showed a welllooking infant, presenting with a pulsatile mass with a palpable thrill in concordance with cardiac contractions. An electrocardiogram showed a normal sinus rhythm (150bpm) with a right deviation of the QRS axis and right ventricle hypertrophy signs.

Echocardiography showed a normal left ventricle with conserved contractility. Important dilatation of the right ventricle and a ventricular septum defect were seen. Both the aorta and pulmonary artery arose from the right ventricle, and the pulmonary artery was posterior to the aorta (Figure 1). Abnormal flow was seen in the cardiac apex.

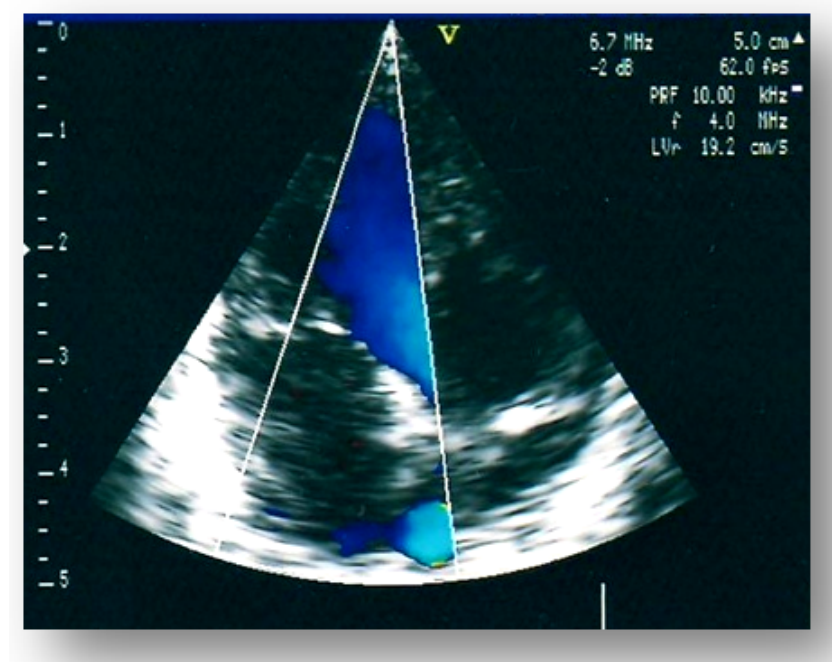

Figure 1. Congenital left ventricular diverticulum on echocardiography. Echocardiography showing abnormal flow in the left ventricle apex.
A 64-channel multi-detector CT (GE LightSpeed VCT) was performed for additional characterization. Sedation of the infant was not necessary. Thoracoabdominal helicoidal acquisition after the injection of non-ionic contrast agent was realized in a cranio caudal direction. The contrast enhanced multi-slice CT showed a thin walled channel extending up from the left ventricular apex to the anterior abdominal wall (Figure 2). This diverticulum was $6 \mathrm{~cm}$ long following the abdominal midline through a defect of the anterior diaphragm and extending up to the umbilical region (Figure 3).



Figure 2. Diagnosis of congenital left ventricular diverticulum on CT scan. Volume rendered 3D CT image showing a diverticulum originating from the left ventricle free wall.

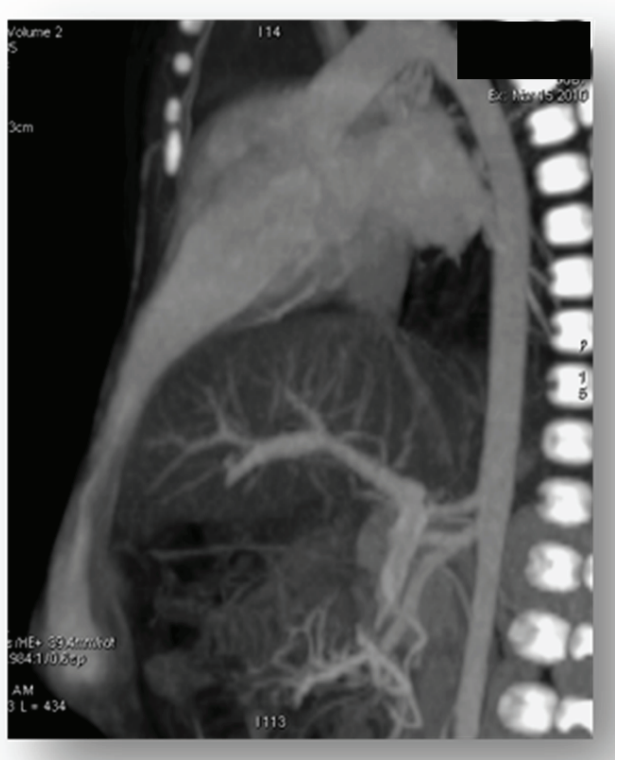

Figure 3. Extent of congenital left ventricular diverticulum on CT scan. Mid-sagittal maximum intensity projection (MIP) thin CT image shows the diverticulum extending up to the umbilical region. 
Myocardial thickness of the outpouching was 3mm (Figure 4A). No herniating bowels were seen (Figure 4B). The examination did not show any other abnormality of intra abdominal organs.

The multi detector CT scan also confirmed the dextro transposition of the aorta and pulmonary artery (Figure 5) and the ventricular septum defect.

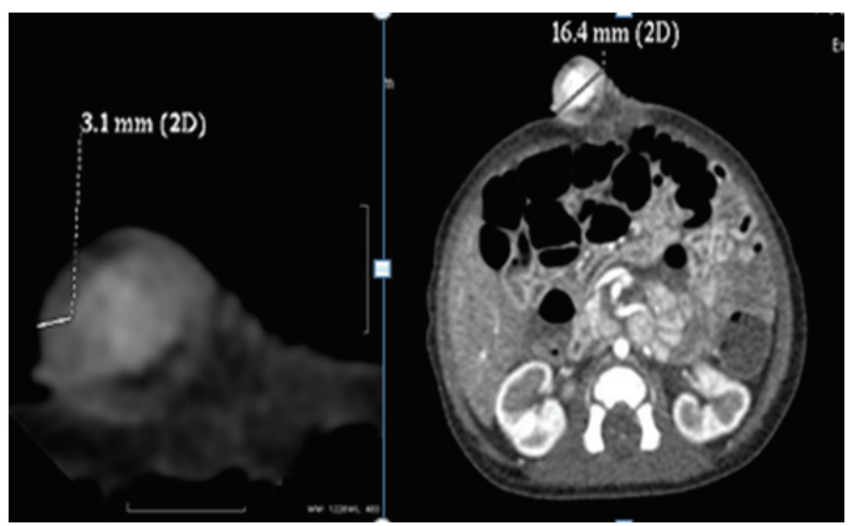

Figure 4. Diagnosis of congenital left ventricular diverticulum associated with the defect of the anterior abdominal wall on CT scan. (A) Axial maximum intensity projection (MIP) CTscan showing the diverticulum wall consisting of a $3 \mathrm{~mm}$ thick myocardium. (B) Axial enhanced multiple detector CT shows the defect of the anterior abdominal wall without herniating bowels.

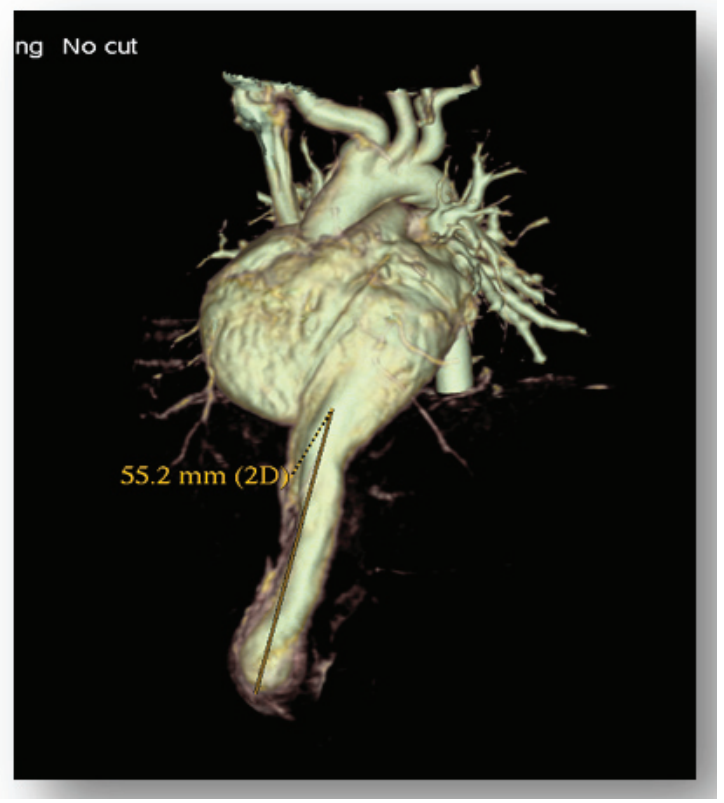

Figure 5. Diagnosis of dextro transposition of the great vessels associated with congenital left ventricular diverticulum on CT scan. Volume rendered 3D CT image showing the dextro transposition of the great vessels.
Surgical treatment was decided upon. The patient was connected to cardiopulmonary bypass and the diverticulum was opened and resected. The entry site was obliterated with a polytetrafluoroethylene patch. Further inspection revealed a normal-sized left ventricle and normal-sized coronary arteries, with no coronary aneurysms. Overlapping reconstruction of the abdominal anterior wall and diaphragm defects were also performed without using any prosthetic material.

The postoperative period was uneventful, and the child was discharged from the hospital on the sixth postoperative day. We proposed medical management for our patient, comprising aspirin at a dosage of $5 \mathrm{mg} / \mathrm{kg} /$ day to prevent any thromboembolic situation.

At a 6 month follow-up examination, the infant had a good clinical condition and a normal cardiac function on echocardiography.

\section{Discussion}

Congenital left ventricular diverticulum is a rare cardiac malformation. Its incidence has been reported to be approximately $0.04 \%$ in the general population and approximately $0.02 \%$ in a consecutive pediatric autopsy series ${ }^{2,4}$. Although ventricular diverticulum may exist alone, it can also be associated with cardiac, vascular, or thoracoabdominal abnormalities ${ }^{4-6}$. In fact, cardiovsacular desease is a component of Cantrell's pentalogy in some patients ${ }^{3}$. Cantrell's pentalogy consists of a defect in the lower sternum, a supra umbilical abdominal wall defect, a deficiency of the anterior portion of the diaphragm, a deficiency in the diaphragmatic portion of the pericardium, and a congenital heart defect ${ }^{2}$.

Patients with isolated cardiac diverticulum are usually asymptomatic; however, there are reports associated with arrhythmias, embolic events, and even death due to diverticulum rupture ${ }^{2}$. Spontaneous rupture occurs very frequently, and can be explained by an increase in pressure inside the diverticulum as a result of a difference in the phase of contraction between the left ventricle and the diverticulum ${ }^{7}$.

Patients with a diverticulum sometimes present with an abnormal electrocardiogram ${ }^{8,9}$. In the case of our patient, a right deviation of the QRS axis and right ventricle hypertrophy signs were noted. Accurate diagnosis cans be made with ultra sonography or echocardiography ${ }^{2-10}$, and prenatal diagnostics have been reported in the literature $^{5}$. CT angiography, MRI and invasive ventriculography give a clearer picture of the problem ${ }^{1,11}$. In the case of our patient, the diagnosis was suspected on echocardiography, and the CT angiography allowed a complete study of the pathology and confirmed the association with other cardiac, diaphragmatic and abdominal abnormalities. Surgical treatment is usually recommended when left ventricular diverticulum is associated with other cardiac or abdominal abnormalities. Perioperative management requests a multidisciplinary experienced team, due to the complexity of cardiac and thoraco abdominal abnormalities associated in Cantrell's syndrome ${ }^{7}$. Recently, the field of percutaneous correction for congenital left ventricular diverticulum has witnessed tremendous 
development and a percutaneous transcatheter device treatment was reported $^{12}$.

The strength of our study is the completeness of the observation with a 6 month follow-up. However, the limitation of our case is the absence of the full perioperative findings.

In conclusion, congenital left ventricular diverticulum is a rare cardiac malformation. The prognosis of this malformation is poor if not diagnosed in the perinatal period. Complications, such as embolism, infective endocarditis, arrhythmia and, rarely, rupture can occur. Although it may exist alone, it can also be associated with cardiac, vascular, or thoracoabdominal abnormalities (e.g., Cantrell's syndrome). A diagnosis can be suspected with echocardiography. CT angiography allow a complete study of the problem. The treatment is always surgical with good postoperative prognosis.

\section{Consent}

Written informed consent for publication of their clinical details and/or clinical images was obtained from the parent of the patient.

\section{Author contributions}

All authors were involved in the revision of the draft manuscript and have agreed to the final content.

\section{Competing interests}

No competing interests were disclosed.

\section{Grant information}

The author(s) declared that no grants were involved in supporting this work.
1. Shah D, Kumar CP, Shah MS, et al.: Case series: Congenital left ventricula diverticulum. Indian J Radiol Imaging. 2010; 20(3): 211-4. PubMed Abstract | Publisher Full Text | Free Full Text

2. Ruiz-Esparza E, Roldan FJ, Vazquez-Antona C, et al.: 2D and 3D echocardiography of a left ventricular diverticulum. Echocardiography. 2009; 26(9): 1087-8.

PubMed Abstract | Publisher Full Text

3. Cantrell JR, Haller JA, Ravitch MM: A syndrome of congenital defects involving the abdominal wall, sternum, diaphragm, pericardium and heart. Surg Gynecol Obstet. 1958; 107(5): 602-14. PubMed Abstract

4. Binnetoğlu FK, Altun G, Kaya A, et al.: Congenital left ventricular diverticulum associated with congenital ileo-jejunal atresia. Pediatr Cardiol. 2012; 33(7): 1224-6. PubMed Abstract | Publisher Full Text

5. Erek E, Odemis E, Tanidir IC: Right-ventricular diverticulum and associated cyst. Pediatr Cardiol. 2013; 34(8): 2093-5 PubMed Abstract | Publisher Full Text

6. Quandt D, Dave H, Valsangiacomo Buechel E: Heart with a trunk: form fruste of Cantrell's Syndrome. Eur Heart J. 2011; 32(1): 123. PubMed Abstract | Publisher Full Text
7. Suehiro K, Okutani R, Ogawa S, et al.: Perioperative management of a neonate with Cantrell syndrome. J Anesth. 2009; 23(4): 572-5. PubMed Abstract | Publisher Full Text

8. Wang W, Zhu W, Wang $\mathrm{Y}$, et al:: Congenital left ventricular diverticulum manifested as T-wave inversion in a child. Pediatr Cardiol. 2010; 31(6): 881-3. PubMed Abstract | Publisher Full Text

9. Gorgels AP: No value of the ECG in congenital left ventricular aneurysms and diverticula? Europace. 2009; 11(12): 1577-8. PubMed Abstract | Publisher Full Text

10. Park SD, Shin SH, Kim DH, et al.: Three-dimensional contrast echocardiography in assessing left ventricular diverticulum. Echocardiography. 2012; 29(9): E230-2. PubMed Abstract | Publisher Full Text

11. Dwivedi AN, Thangiah AG, Rai M, et al:: Computed tomographic features of congenital left ventricular diverticulum. J Clin Imaging Sci. 2012; 2: 48. PubMed Abstract | Publisher Full Text | Free Full Text

12. Jain S, Mahajan R, Rohit MK: Percutaneous transcatheter device closure of an isolated congenital LV diverticulum: first case report. Pediatr Cardiol. 2011; 32(8): 1219-22.

PubMed Abstract | Publisher Full Text 


\section{Open Peer Review}

\section{Current Peer Review Status: ? ?}

\section{Version 1}

Reviewer Report 29 December 2016

https://doi.org/10.5256/f1000research.10707.r18844

(c) 2016 Soynov I. This is an open access peer review report distributed under the terms of the Creative Commons Attribution License, which permits unrestricted use, distribution, and reproduction in any medium, provided the original work is properly cited.

\section{Ilya Soynov}

Department of Pediatric Cardiac Surgery, Novosibirsk State Research Institute of Circulation Pathology, Novosibirsk, Russian Federation

This case is very interesting because of the combination Cantrell's pentalogy and transposition of great arteries is extremely rare.

But there are several questions to the authors.

I have a doubt of the presence of transposition of the great arteries on CT scans in the article. On the scans it seems that the pulmonary artery arises in front of the aorta (anterior). I think you need to provide another scan where it would clearly show the location of the great vessels.

There are not data about LV volume before and after the surgery. Where was the VSD? Sizes?

Surgery is preferable in patients with symptoms of heart failure or in those with complications caused by left ventricle diverticula, whereas resection in asymptomatic patients remains controversial. What was the indication to resection of the diverticulum?

There is little information about surgery. You wrote that "Surgical treatment is usually recommended when left ventricular diverticulum is associated with other cardiac or abdominal abnormalities" but there is not any information about the surgery of TGA. Did you preform the correction of TGA and VSD simultaneously or not? What were the time of aortic cross clamp and CPB? Currently, there is no single generally accepted method for the resection of left ventricle diverticula or for left ventricle reconstruction. What did you do in this case?

Competing Interests: No competing interests were disclosed.

I confirm that I have read this submission and believe that I have an appropriate level of 
expertise to confirm that it is of an acceptable scientific standard, however I have significant reservations, as outlined above.

Reviewer Report 18 November 2016

https://doi.org/10.5256/f1000research.10707.r17737

(C) 2016 Alwi M. This is an open access peer review report distributed under the terms of the Creative Commons Attribution License, which permits unrestricted use, distribution, and reproduction in any medium, provided the original work is properly cited.

\section{Mazeni Alwi}

Department of Paediatric Cardiology, Institut Jantung Negara, Kuala Lumpur, Malaysia

This is an interesting case report of congenital LV diverticulum in the setting of Cantrell's syndrome. The authors describe well the clinical findings and imaging techniques with echocardiography of MDCT and contrast angiography which confirmed the diagnosis. Advances in non-invasive imaging have played an important role in confirming rare congenital cardiac anomalies such as this.

The patient underwent surgical resection of diverticulum, however there was no mention of treatment of the co-existing congenital heart disease, namely double outlet right ventricle, ventricular septal defect and transposition of great artery (DORV-TGA-VSD). Was this done at the same time? That the patient was well at 6 months review, does this mean that the major cardiac abnormalities were also repaired? If so, how did resection of the diverticulum impact or repair of the other cardiac anomalies?

Secondly, in the "discussion" section (para3, line 1-3), the authors state that patients with a diverticulum sometimes present with an abnormal ECG, as did their patient who had right axis deviation and right ventricular hypertrophy. This abnormality is likely to attributed to the DORVTGA-VSD rather than the LV diverticulum.

Competing Interests: No competing interests were disclosed.

I confirm that I have read this submission and believe that I have an appropriate level of expertise to confirm that it is of an acceptable scientific standard, however I have significant reservations, as outlined above.

Author Response 19 Nov 2016

Myriam Jrad, La Rabta Hospital, Tunis, Tunisia

Firstly, thank you for your interesting comments.

Indeed, given the heaviness of the operation and the lack of means of anesthesia in our department at this age the abnormality of large vessels was treated at the age of 1 year. Secondly, it has been described in the literature that the abnormalities described with the 
ECG during this pathology are not specific and this can be explained by an associated cardiac disease what is the case of our patient.

Competing Interests: No competing interests were disclosed.

The benefits of publishing with F1000Research:

- Your article is published within days, with no editorial bias

- You can publish traditional articles, null/negative results, case reports, data notes and more

- The peer review process is transparent and collaborative

- Your article is indexed in PubMed after passing peer review

- Dedicated customer support at every stage

For pre-submission enquiries, contact research@f1000.com 